\title{
CNS Myelin and Oligodendrocytes of the Xenopus Spinal Cord-but Not Optic Nerve-Are Nonpermissive for Axon Growth
}

\author{
Dirk M. Lang,' Beatrix P. Rubin, ${ }^{2}$ Martin E. Schwab, ${ }^{2}$ and Claudia A. O. Stuermer ${ }^{1}$ \\ ' University of Konstanz, Faculty of Biology, D-78434 Konstanz, Germany and ${ }^{2}$ Institute for Brain Research, University of \\ Zürich, $\mathrm{CH}-8029$ Zürich, Switzerland
}

In vitro assays reveal that myelin and oligodendrocytes of the Xenopus spinal cord (SC) are-unlike corresponding components of the optic nerve/tectum (OT)-nonpermissive substrates for regenerating retinal axons. The number of growth cones that crossed SC oligodendrocytes is low but increases significantly (four- to fivefold) in the presence of the antibody IN-1, in which case their numbers are similar to the number of growth cones $(\sim 60 \%)$ that cross OT ofigodendrocytes with or without IN-1. IN-1 neutralizes neurite growth inhibitors (NI) of rat CNS myelin, indicating that mammalian-like NI are associated with Xenopus SC myelin and oligodendrocytes but not with the OT. IN-1 immunocytochemistry on sections supports this view: SC myelin was stained with IN-1, whereas OT myelin and PNS myelin were not.

[Key words: CNS myelin/oligodendrocytes, Xenopus, differences in substrate properties, neurite growth inhibitors, in vitro assays, $[\mathrm{N}-1 \mathrm{immunocytochemistry]}$

While a variety of factors contribute to the success or failure of axonal regeneration in the vertebrate CNS, the influence exerted by neurite growth inhibitors of oligodendrocytes and CNS myelin (Caroni and Schwab, 1988a) on injured CNS axons is widely recognized (Schwab et al., 1993). Growth cones of various origin, such as dorsal root ganglia (DRG) (Bandtlow et al., 1990), locus coeruleus (Moorman and Hume, 1993), and retinal ganglion cells (Fawcett et al., 1989; Vanselow et al., 1990; Bastmeyer et al., 1991; Kapthammer et al., 1992) collapse when they contact oligodendrocytes (Bandtlow et al., 1990; Bastmeyer et al., 1991), CNS myelin (Moorman and Hume, 1993), or the purified cell surface proteins (Bandtlow et al., 1993). Collapse responses are, however, markedly reduced in the presence of the monoclonal antibody (Mab) IN-1 (Caroni and Schwab, 1988b; Bandtlow et al., 1990), which is known to neutralize the

\footnotetext{
Received Mar. 22, 1994; revised May 27, 1994; accepted June 8, 1994.

We thank Pate Skene, who drew the attention of one of us (C.A.O.S.) to Xenopus CNS fiber regeneration and thus contributed decisively to the initiation of this study. We further thank Christopher Linington (Munich) and Ben Szaro (Albany), who provided us with relevant antibodies. We are grateful to Mary Anne Cahill for correcting the manuscript and for the electron microscopy and to Doris Bliestle's photography department for the prints. D.M.L. is supported by a grant of the Boehringer-Ingelheim Foundation to perform his dissertation. Further financial support is provided by a grant of the Deutsche Forschungsgemeinschaft and of the Gemeinnützige Hertie-Stiftung to C.A.O.S. B.P.R. and M.E.S. are supported by the Swiss National Science Foundation.

Correspondence should be addressed to Prof. Dr. Claudia Stuermer, University of Konstanz, Faculty of Biology, P.O. Box 5560, M 625, D-78434 Konstanz, Germany.

Copyright $(1) 1995$ Society for Neuroscience $0270-6474 / 95 / 150099-11 \$ 05.00 / 0$
}

inhibitory activity. Growth impairment by CNS myelin and oligodendrocytes is also observed in the chick (Keirstead et al., 1993).

In the CNS of fish, axons regenerate successfully in both the optic nerve (Gaze, 1970) and spinal cord (Sharma et al., 1993) and there is evidence that myelin-associated neurite growth inhibitors are either absent (Carbonetto et al., 1987; Caroni and Schwab, 1988a; Bastmeyer et al., 1991) or expressed at such low levels that they do not interfere with axonal regeneration in the fish CNS. Furthermore cross-species time-lapse studies of axon-oligodendrocyte encounters using the antibody IN-1 against rat myelin neurite growth inhibitors (Caroni and Schwab, 1988b) have demonstrated that goldfish retinal axons are sensitive to the mammalian inhibitor proteins (Bastmeyer et al., 1991). The spontaneous and robust axonal regeneration found in the fish optic nerve and spinal cord may - to a considerable degrec-be attributed to the permissive substratc properties of fish oligodendrocytes and CNS myelin.

In adult frogs (Anura), optic nerve fibers regenerate (for review, see Gaze, 1970) and early studies indicated that neurite growth inhibitors are not present in frog CNS myelin (Caroni and Schwab, 1988a). However, spinal cord fiber tracts fail to regenerate in adult frogs (Forehand and Farel, 1982; Beattie et al., 1990) whereas spinal cord regeneration is successful in tadpoles (Forehand and Farel, 1982; Beattie et al., 1990), suggesting that certain conditions in the frog CNS must change as they approach and complete metamorphosis. Urodeles, like fish, are capable of lifelong regeneration of injured axons in their optic nerves (Turner and Singer, 1974; Stensaas and Feringa, 1977) and spinal cords (Piatt, 1955; Clarke et al., 1988).

We therefore asked whether success or failure of axonal regeneration in the amphibians Xenopus and axolotl is also correlated with permissive versus non-permissive substrate properties of oligodendrocytes and CNS myelin.

The experiments were as follows. (I) In a quantitative outgrowth assay (Vielmetter and Stuermer, 1989; Bastmeyer et al., 1991), the substrate properties of CNS myelin of adult Xenopus optic nerve/tectum as opposed to spinal cord were examined and compared to those of CNS myelin of axolotls, goldfish and rats. Explants from adult goldfish retina were used because they are large and can yield as many as $\mathbf{3 0 0}$ miniexplants, thus allowing their distribution over wells with different myelin preparations, and because regenerating goldfish retinal axons are known to respond distinctively to various substrates including myelin (Bastmeyer et al., 1991). (2) The reaction of growing axons (from goldfish and Xenopus) encountering oligodendrocytes from optic nerve/tectum or spinal cord of Xenopus was analyzed with time-lapse video microscopy and (3) such ex- 


\section{Quantitative Outgrowth Assay: Goldfish RGC Axons on Myelin Substrates}

Figure 1. Comparison of the number of regenerating goldfish retinal axons extending on a substrate consisting of CNS myelin. The height of each column represents the mean number of axons. The SE is indicated at the top of each column. The means are printed into each column to facilitate reading. The total number of microexplants $(n)$ are given above each column. OT, optic nerve/tectum; $C N S$, central nervous system; $S C$, spinal cord.

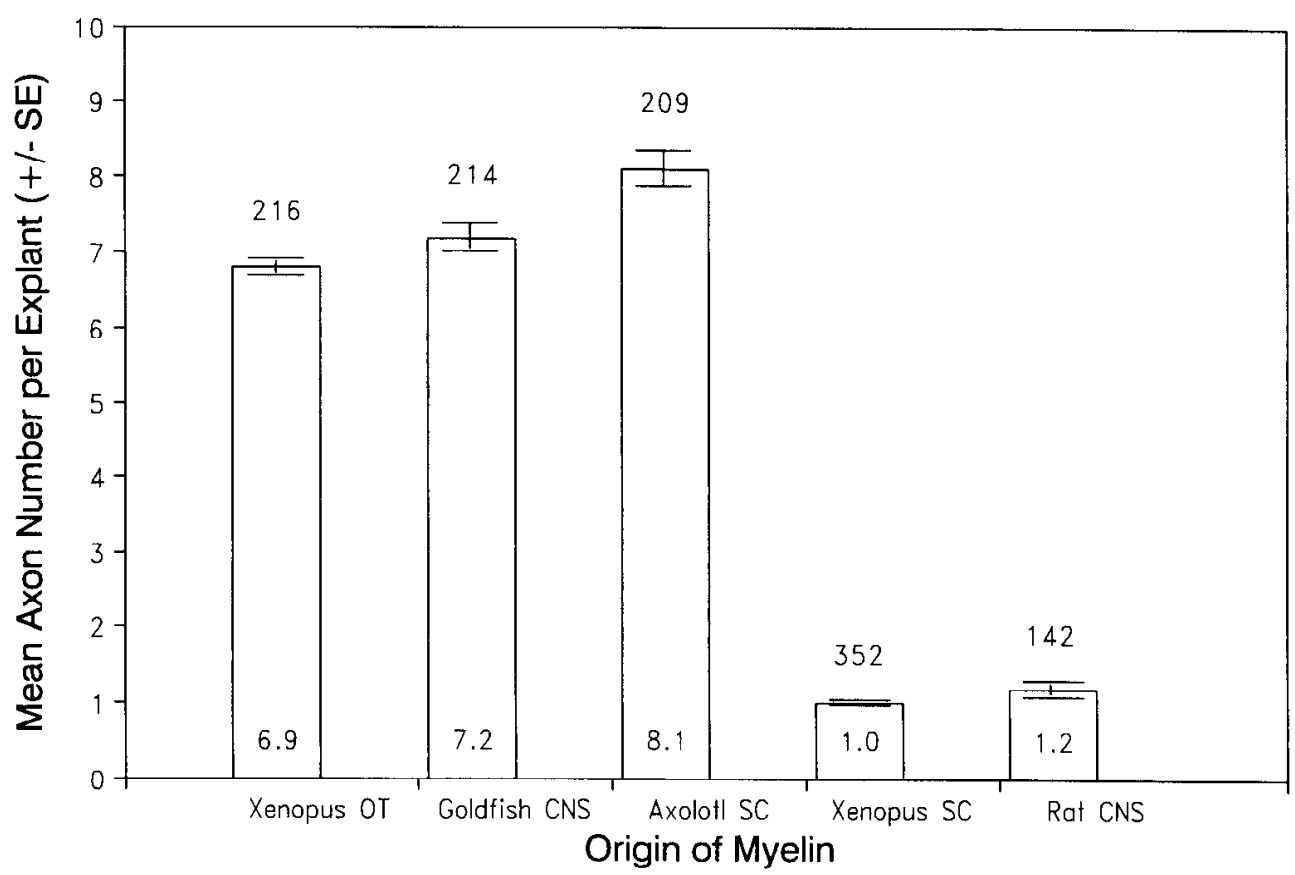

periments were also performed in the presence of Mab IN-1. (4) The extent of myelination in the adult Xenopus CNS was determined and immunostaining procedures (Rubin et al., 1994) using Mab IN-1 were used to visualize the distribution of the myelin-associated neurite growth inhibitors. (5) The development of myelination and IN-1 immunoreactivity was analyzed in Xenopus tadpoles and during metamorphosis.

The present results confirm a correlation between nonpermissive substrate properties of (and presence of IN-1 immunoreactivity on) oligodendrocytes and CNS myelin and failure of axonal regeneration in adult Xenopus spinal cord. They also show a correlation between the permissive properties of CNS myelin and oligodendrocytes (and absence of IN-1 immunorcactivity) and lengthy axon regrowth in its optic nerve.

Preliminary accounts of this work were published as abstracts (Lang et al., 1993; Stuermer and Lang, 1993).

\section{Materials and Methods}

Animals. Axolotls were kindly provided by J. Kaufman (Basel Institute for Immunology). All other animals used in the experiments were bred and maintained at the animal research unit of the University of Constance in compliance with animal welfare legislation.

Immunostaining of cryosections. Animals were deeply anesthetized in a $0.1 \%$ solution of MS 222 (Sandoz), nervous tissue was dissected, rinsed twice in ice-cold PBS, embedded in Tissue-Tek (Miles Inc.), and frozen in liquid Nitrogen. Ten-micrometer sections were fixed in methanol $\left(5 \mathrm{~min}\right.$ at $\left.-20^{\circ} \mathrm{C}\right)$ or, for staining with Mab IN-1, in ethanol containing $5 \%$ acetic acid $\left(25 \mathrm{~min}\right.$ at $\left.4^{\circ} \mathrm{C}\right)$ and treated according to the
Vectastain ABC Elite (Vector Laboratories) standard procedure. A rabbit polyclonal antiserum (IgG fraction) to rat proteolipid protein (PLP) and rat hybridoma supernatants against guinea pig myelin basic protein (MBP) (both kindly provided by C. Linington) were employed as myelin markers at a dilution of 1:500 and 1:5, respectively. Hybridoma supernatant containing Mab IN-l (mouse IgM) against the myelin-associated inhibitors was used undiluted. Incubation with primary antibodies was either $2 \mathrm{hr}$ at $37^{\circ} \mathrm{C}$ or overnight at $4^{\circ} \mathrm{C}$. The appropriate secondary antibodies coupled to RITC or FITC were purchased from Dianova.

Sections of Xenopus spinal cord, optic nerve, PNS nerve, and axolotl spinal cord were collected on the same slide and exposed to identical immunostaining procedures. The observations that IN-1 immunostaining was selective rules out unspecific binding of the IN-1 antibody to amphibian tissue.

Cultures enriched in Xenopus oligodendrocytes. The CNS of anesthetized tadpoles (Nieuwkoop and Faber stages 53-66) or of froglets up to $10 \mathrm{~d}$ after metamorphosis was dissected in L-15 medium (GIBCO). The tissue was freed of meninges and peripheral nerve roots. Optic nerve, tectum and spinal cord were separated, cut into small pieces on a McIlwain tissue chopper, and rinsed twice in L-15 containing $10 \%$ fetal calf serum (FCS; GIBCO). Tissue fragments were spun down briefly with low speed centrifugation and resuspended in culture medium consisting of $80 \%$ DMEM/Ham's F-12 (GIBCO) $1: 1$ and $20 \%$ doubledistilled water, supplemented with $10 \%$ FCS, $0.4 \%$ methyl cellulose (Sigma), $15 \mathrm{~mm}$ HEPES, $3.5 \mathrm{mg} / \mathrm{ml}$ glucose, $0.1 \mathrm{mg} / \mathrm{ml}$ glutamine, $5 \times$ $10^{-3} \mathrm{mg} / \mathrm{ml}$ bovine insulin, $10^{-4} \mathrm{M}$ putrescine, $2 \times 10^{-8} \mathrm{M}$ progesterone, $3 \times 10^{-8} \mathrm{M}$ Na-selenite (all Sigma), and $5 \times 10^{-2} \mathrm{mg} / \mathrm{ml}$ gentamicin (GIBCO). The tissue pieces were explanted onto polylysine/laminincoated coverslips (Bastmeyer et al., 1989). A second coverslip was placed on top and held in place by stainless steel spacers, thus forming a sandwich of two coverslips with the culture medium suspended in between. This arrangement was placed in a plastic culture dish (Greiner)

Figure 2. Growth cone/oligodendrocyte encounters. $a$, Differentiated oligodendrocytes derived from the Xenopus spinal cord after exposure to forskolin. Oligodendrocytes exhibit a highly branched morphology and are immunostained with GalC-antibodies. $b$ and $c$, The majority of growth cones avoid crossing O1-positive $(c)$ spinal cord-derived oligodendrocytes $(b)$, and instead grow around the perimeter of the glial cell $(a r r o w h e a d s)$. $d$ and $e$, The majority of growth cones can grow over O1-positive oligodendrocytes $(e)$ derived from the Xenopus optic nerve. Axons $(d)$ are marked by arrowheads. Scale bars, $100 \mu \mathrm{m}$. 

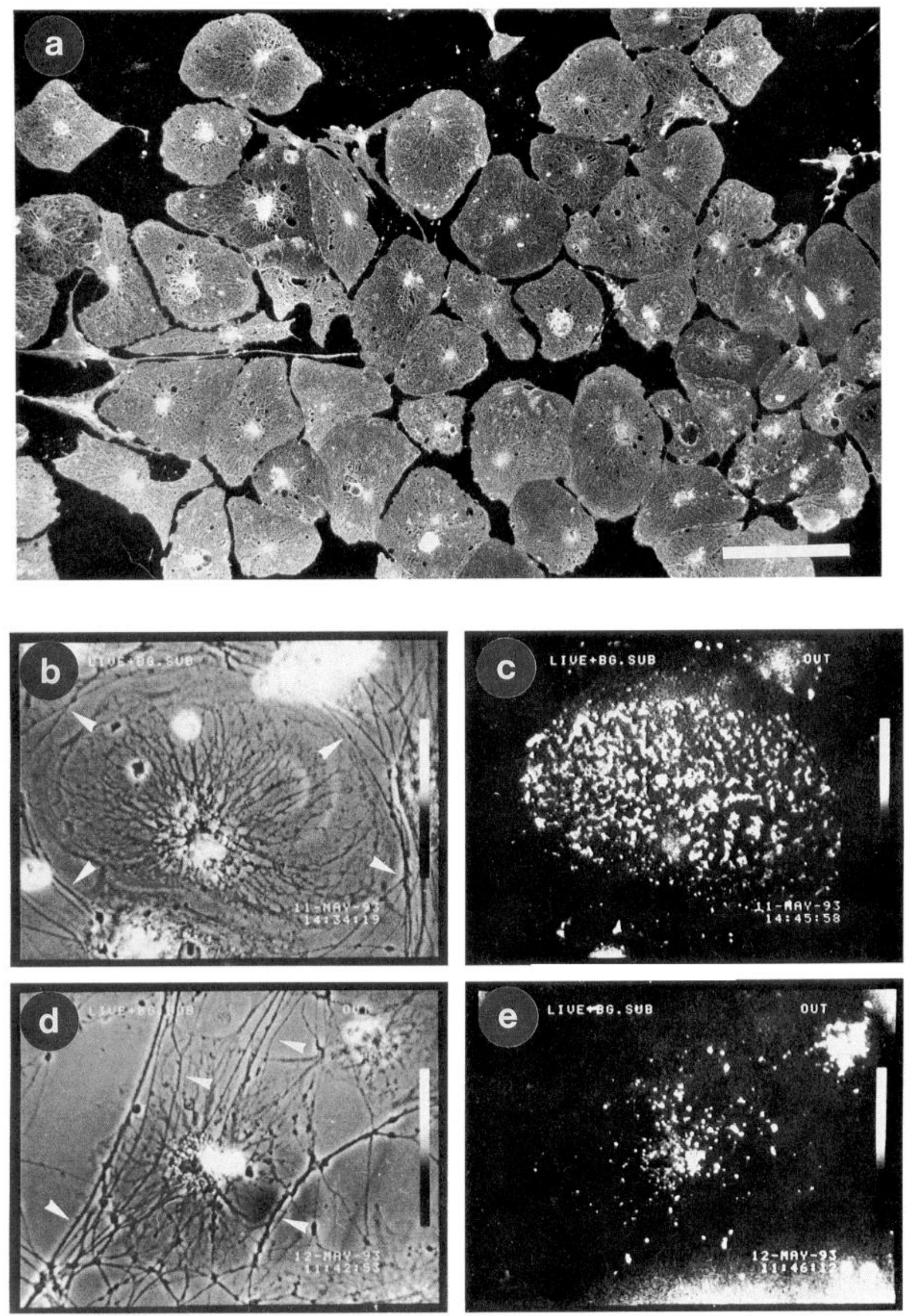
and incubated in a humidified chamber at $22^{\circ} \mathrm{C}$. Glial cells emigrated from the explants and multiplied over several weeks with a change of medium twice a week. Under these culture conditions the number of differentiated oligodendrocytes remained small, but a large number of differentiating oligodendrocytes was obtained by addition of $10 \mu \mathrm{M}$ forskolin (Biomol) to the culture medium.

Immunocytochemical characterization of oligodendrocyte cultures. Cultures were treated for indirect immunofluorescence either as described previously (Bastmeyer et al., 1991) or according to the Vectastain ABC Elite standard procedure (Vector Laboratories). Staining with Mabs Ol and O4 (mouse IgM, Sommer and Schachner, 1981) was performed by incubating live cultures with hybridoma supernatant diluted $1: 3$ in $\mathrm{L}=15$ (30 $\mathrm{min}$ at room temperature). Anti-GalC (galactocerebroside) Mab (mouse IgG, Boehringer Mannheim) was used at a dilution of 1:10. Antisera to rat PLP and Mabs against MBP were applied to fixed cells at dilutions of $1: 500$ and 1:5, respectively, either for $2 \mathrm{hr}$ at $37^{\circ} \mathrm{C}$ or overnight at $4^{\circ} \mathrm{C}$.

Cocultures of retinal axons and oligodendrocytes. Goldfish retinal explants were prepared as described previously (Vielmetter and Stuermer, 1989). Xenopus retinal explants were obtained from postmetamorphic frogs that had, as was the case for goldfish, received a conditioning optic nerve cut 10-14 d prior to preparation (Landreth and Agranoff, 1976). Eyes were removed, and the retinas were isolated in L-15, attached to a nylon filter (Hybond, Amersham) with the photoreceptor layer down, and cut into segments $300 \mu \mathrm{m}$ wide. They were explanted with their ganglion cell layer down onto coverslips containing oligodendrocytes that were rinsed in culture medium before use. Filter strips with retina were held in place by stainless steel spacers with a second coverslip on top. Cocultures were transferred to Petriperm dishes (Heraeus) and incubated at $22^{\circ} \mathrm{C}$ in a humidified chamber. Supernatant containing Mab $\mathrm{Ol}$ or anti-GalC Mab were added to several cocultures in dilutions of $1: 3$ and $1: 10$, respectively, to facilitate identification of oligodendrocytes.

For functional assays with Mab IN-1, cocultures were grown in culture medium containing 50\% IN-1 hybridoma supernatant. In control experiments, Mab O1 (diluted 1:2) was used instead of IN-1. Hybridomas producing IN-1 (and O1) antibodies are raised in Iscove's medium. This medium alone impaired the growth of goldfish (Bastmeyer et al., 1991) and Xenopus retinal axons. Therefore, Mabs IN-1 and O1 in Iscove's medium were dialyzed against L-15 before use. Dialyzed IN-1 and O1 antibodies still stained myelinated fiber tracts in Xenopus spinal cord. That dialyzed IN-1 retains its activity (i.e., neutralizing the neurite growth inhibitors) was demonstrated in experiments with rat oligodendrocytes (Bastmeyer et al., 1991) and in this study (see Results, paragraph 3).

Time-lapse video microscopy. Fncounters of growing retinal axons with oligodendrocytes were observed as before (Bastmeyer et al., 1991) with an inverted microscope (Zeiss Axiovert) at room temperature using a $40 \times$ lens and phase contrast optics. The light path was automatically opened for $250 \mathrm{msec}$ at $5 \mathrm{sec}$ intervals. Images were recorded by a video camera, transferred to an image processing system (Hamamatsu DVS 3000) and stored on videotape (S-VHS). Pictures of single frames were obtained through a video printer.

Myelin preparation and quantitative outgrowth assay. CNS myelin from adult rat brain and spinal cord as well as goldfish CNS myelin was prepared as described in Bastmeyer et al. (1991), except that sucrose step gradient centrifugation was repeated twice. CNS myelin from Xenopus optic nerve, tectum, and spinal cord as well as from axolotl spinal cord was obtained by centrifugation of homogenized tissue in a $15 \%$, $25 \%$, and $50 \%$ sucrose step gradient at $75,000 \times g$ for $10 \mathrm{~min}$ in the presence of protease inhibitors (modified after Colman et al., 1982). Myelin fragments were distributed over wells of 96-well dishes (Nunc; $5 \mu \mathrm{g} /$ well), and centrifuged to adhere to the bottom of the wells.

Mini-explants $(200 \times 200 \mu \mathrm{m})$ of goldfish retinas (Vielmetter and Stuermer, 1989; Bastmeyer et al., 1991) were pipetted one into each well, and thus came to lie either ganglion cell layer up or down on the myelin carpet. Outgrowth of axons occurs only from the latter, and from the entire circumference of the explant. This facilitates counting, which is performed after fixation with $\mathbf{4 \%}$ glutaraldehyde in $0.1 \mathrm{~m}$ phosphate buffer, $48 \mathrm{hr}$ after explantation under the microscope with a $10 \times$ lens and phase contrast. Axons that join to form small fascicles can, in most cases, be seen as individuals close to their exit from the explant (Vielmetter and Stuermer, 1989), but if not, a fascicle is counted as one axon. Counts were averaged over all explants (with and without axons) and used as a measure for the growth permissivity of the various myelin fractions.
Electron microscopy. Xenopus optic nerves and spinal cords were, after dissection in PBS, fixed in phosphate-buffered glutaraldehyde (2\%) for $48 \mathrm{hr}$ at $4^{\circ} \mathrm{C}$, transferred to $2 \%$ osmium tetroxide in $0.1 \mathrm{~m}$ phosphate buffer for $1 \mathrm{hr}$ at room temperature, and stained en bloc with uranyl acetate. Sections were counterstained with lead citrate. After dehydration in a graded series of alcohol the tissue was embedded in Epon and ultrathin sections were obtained on a Reichert ultramicrotome. Sections were viewed in a Zeiss EM 900 electron microscope.

\section{Results}

Xenopus spinal cord myelin is a less permissive substrate than myelin from optic nerve/tectum

The number of regenerating axons extending from goldfish retinal microexplants was on the average nearly seven times smaller on myelin of Xenopus spinal cord than on myelin derived from optic nerve/tectum (Fig. 1). Outgrowth on Xenopus spinal cord myelin was in fact as poor as on rat CNS myelin (Fig. 1), whereas Xenopus optic nerve/tectum myelin allowed outgrowth in the same order of magnitude as does goldfish CNS myelin (Fig. 1). Axon numbers were highest on axolotl spinal cord myelin (Fig. 1). These data suggest that Xenopus spinal cord myelin is a nonpermissive substrate for axonal growth, much like rat CNS myelin (Bastmeyer et al., 1991), whereas Xenopus optic nerve/tectum myelin is as permissive as goldfish CNS myelin (Bastmeyer et al., 1991), but not quite as permissive as myelin from the axolotl CNS.

\section{Axon-oligodendrocyte encounters}

The in vitro development of oligodendrocytes from Xenopus optic nerve/tectum and spinal cord was similar and will be described in detail elsewhere (Lang and Stuermer, unpublished observations; Stuermer and Lang, 1993). In brief, elongated oligodendrocyte precursor cells that were negative for $04, \mathrm{Gal}$ C, PLP, or MBP were induced to differentiate simultaneously to round and highly branched oligodendrocytes (Fig. 2). They acquired immunoreactivity to $\mathrm{O} 4, \mathrm{GalC}$, and $\mathrm{O} 1$, and $20 \%$ expressed PLP and MBP.

In two sets of experiments, retina segments from goldfish or Xenopus were explanted onto the coverslips carrying the differentiated oligodendrocytes and axon-oligodendrocyte encountcrs wcre monitored with time-lapse video microscopy. The glial cells were either derived from Xenopus optic nerve/tectum or from its spinal cord. Differentiated oligodendrocytes were identified by their morphology (Fig. 2b,d) and by GalC- and O1antibodies (Fig. 2a,c,e). Goldfish and Xenopus retinal axons extended within $12 \mathrm{hr}$ after explantation and elongated with a velocity of $65-85 \mu \mathrm{m} / \mathrm{hr}$ on the polylysine/laminin substrate. When growth cones came into contact with oligodendrocytes they typically moved onto membranous extensions of the cells, and both growth cones and oligodendrocytes showed ruffling of membranes over a period of up to $2 \mathrm{hr}$.

The growth cones reacted in one of three ways: they collapsed and retracted, withdrew and grew around the cell (avoidance) (Fig. $2 b$ ) or they grew over the cell (Fig. $2 d$ ). The majority of goldfish and Xenopus retinal axons ( $89 \%$ and $84 \%$, respectively) failed to cross spinal cord-derived oligodendrocytes (Fig. 3a,b). In most instances they grew around the cells, but some collapsed.

With oligodendrocytes derived from optic nerve/tectum, retinal growth cones crossed the cells in more than $55 \%$ of all encounters ( $66 \%$ for Xenopus and $58 \%$ for goldfish axons). The rest avoided the cells, but collapse occurred in rare instances (Fig. 3a,b).

The differences in growth cone reactions to oligodendrocytes 


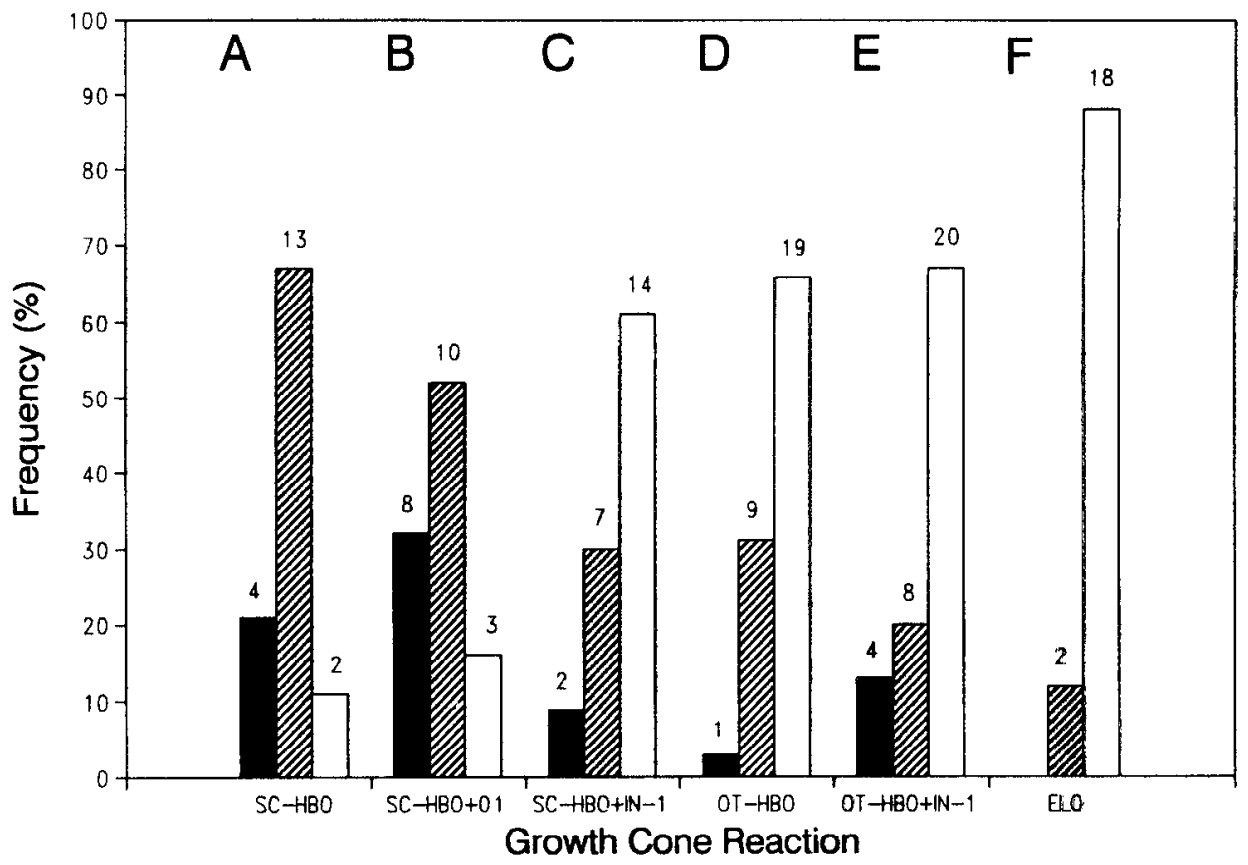

\section{b \\ Coculture Assay: Oligodendrocytes and Xenopus RGC Axons}

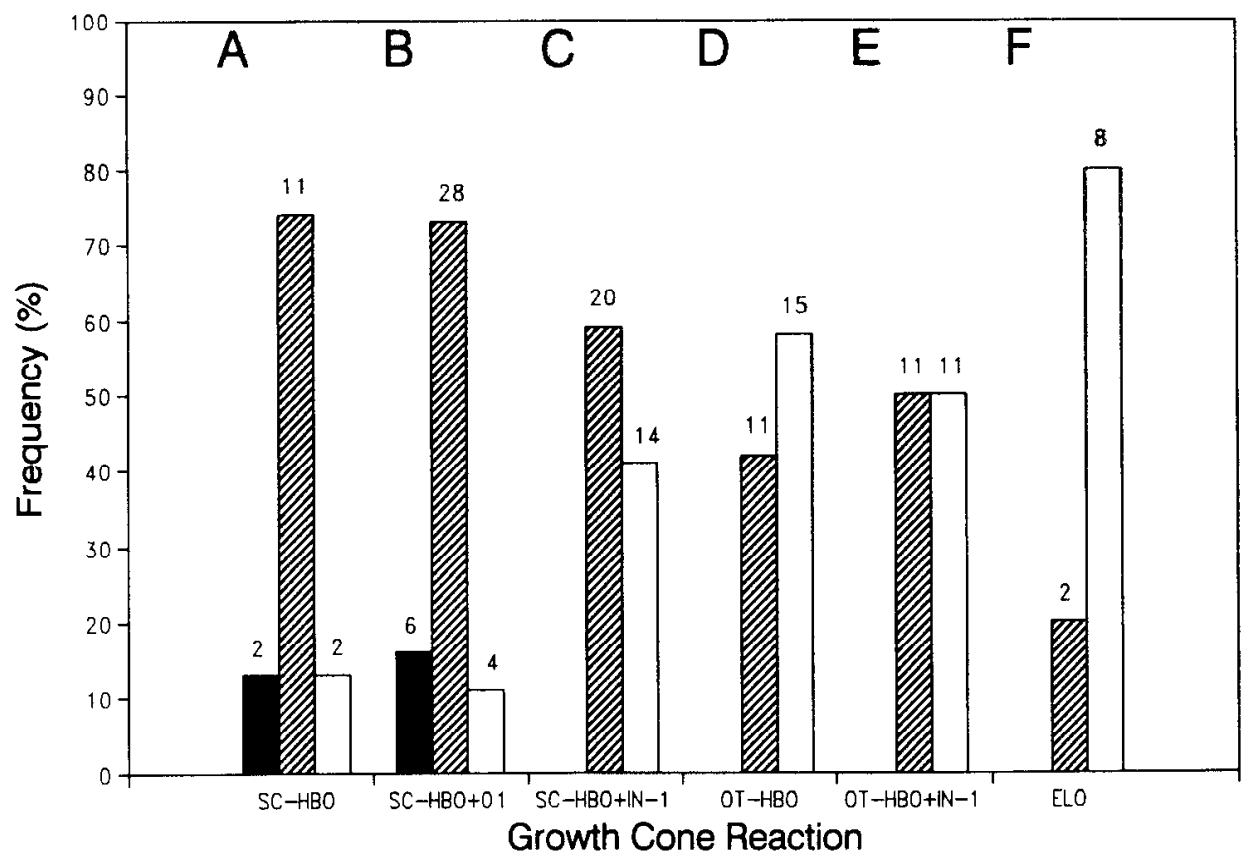

Figure 3. Quantification of growth cone oligodendrocyte encounters in the absence and presence of IN-1 antibody. In $a$ and $b$, bars represent the percentage of growth cones that collapsed ( $\mathrm{sol}$ id), avoided (hatched), or crossed (open) Xenopus oligodendrocytes upon contact, in dependence of the presence or absence of $\mathrm{mAbs} I N-1$ and $\mathrm{O} 1$. The number of growth cones is given at the top of each column. $S C$, spinal cord; $O T$, optic nerve/tectum; $H B O$, highly branched (differentiated) oligodendrocytc; $+I N-1$, in the presence of $\mathrm{mAb}$ $\mathrm{IN}-1 ;+O 1$, in the presence of $\mathrm{mAb} \mathrm{O} 1$; $E L O$, elongated (undifferentiated) oligodendrocyte; $R G C$ axons, regenerating retinal ganglion cell axons. 

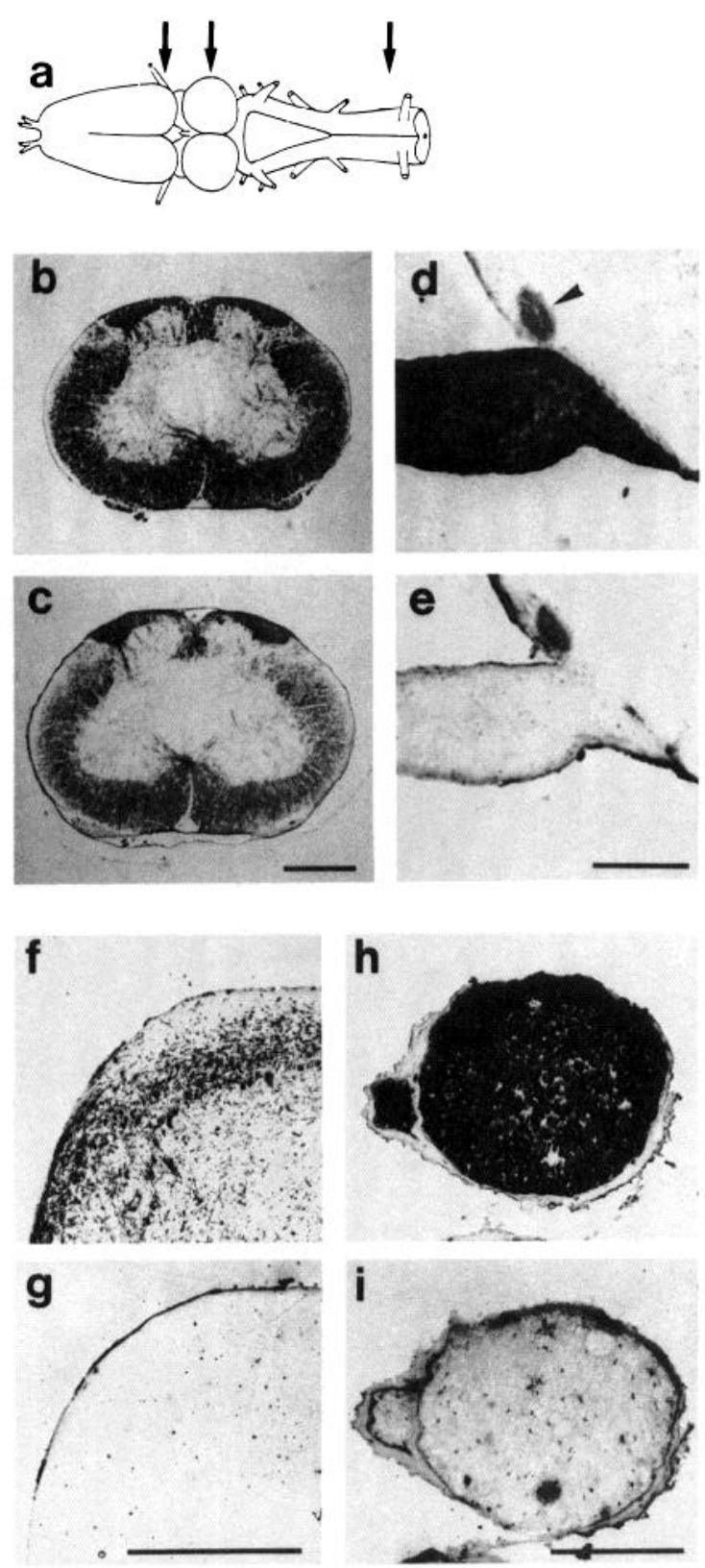

Figure 4. IN-1 immunocytochemistry on sections of the Xenopus CNS and PNS. $a$, Schematic drawing of the Xenopus brain to indicate the origin of sections $b-e$ (arrows). $b$ and $c$, Cross sections through the spinal cord (right arrow in $a$ ), exposed to antibodies against MBP $(b)$ and IN-1 (c). White matter and myelinated fiber tracts crossing through the gray matter are strongly positive for MBP and IN-1. $d$ and $e$, Section of the optic nerve (left arrow in $a$ ). $d$, Immunostained with PLP antibodies to reveal myelination. $e$, Mab IN-1 does not bind to optic nerve myelin. The immunostaining procedure produces unspecific staining of large blood vessels (arrowhead in $d$ ), the meninges and epithelia around the brain and PNS nerves (as in $b-i)$. $f$ and $g$, Section of the optic tectum, (middle arrow in a), immunostained with PLP antibodies $(f)$, or immunostained with Mab IN-1 $(g)$. No IN-1 immunoreactivity is seen, but myelinated tracts are present $(f) . h$ and $i$, Sections of the sciatic nerve (PNS), in which the myelinated axons are stained by MBP-antibodies $(h)$ but not by IN-1 $(i)$. All corresponding figures show consecutive sections. Scale bars, $500 \mu \mathrm{m}$. of optic nerve/tectum and spinal cord were statistically significant ( $\alpha=0.001 ; \chi^{2}$ test after Brandt and Snedecor).

Immature oligodendrocytes proved to be better substrates than differentiated oligodendrocytes of either source, as most growth cones grew from the polylysine/laminin substrate on and over elongated oligodendrocytes (Fig. $3 a, b$ ) without reducing their velocity. Growth cones that crossed differentiated optic nerve/tectum oligodendrocytes progressed more slowly, with a velocity of $40-60 \mu \mathrm{m} / \mathrm{hr}$. The few growth cones that managed to grow across spinal cord oligodendrocytes exhibited an even further decrease in growth velocity and were never faster than $25 \mu \mathrm{m} / \mathrm{hr}$.

These results show that oligodendrocytes from optic nerve/ tectum are more permissive than those of the spinal cord.

\section{Axon-oligodendrocyte encounters in the presence of IN-I}

To determine if neurite growth inhibitors similar to those characterized for rat oligodendrocytes and myelin (Caroni and Schwab, 1988a,b) are involved in growth cone collapse and avoidance responses, similar experiments were performed with the addition of Mab IN-1 to the culture medium and Mab O1 for controls.

As illustrated in Figure 3, $a$ and $b$, the proportion of goldfish and Xenopus retinal axons that crossed spinal cord-derived oligodendrocytes increased in the presence of IN-1 (61\% and $41 \%$, respectively, as apposed to $11 \%$ and $16 \%$ without IN-1). The difference in axonal responses to these oligodendrocytes in the absence or presence of IN-1 was statistically significant $(\alpha=$ 0.001 for goldfish, and $\alpha=0.05$ for Xenopus retinal axons; $\chi^{2}$ test after Brandt and Snedecor). Mab O1 did not have such an effect (Fig. 3a,b).

In contrast to the situation with spinal cord oligodendrocytes, there was no change in growth cone reactions upon contact with oligodendrocytes from optic nerve/tectum in the presence of IN-1 (Fig. 3a,b). This also applied to growth velocities of axons crossing IN-1-treated oligodendrocytes. Growth velocities in the presence of IN-1 were, as before, between 40 and $60 \mu \mathrm{m} /$ hr. However, growth cones that grew over spinal cord oligodendrocytes in the presence of IN-1 gained in speed $(25-45 \mu \mathrm{m} /$ hr) compared to their counterparts that encountered such cells in O1-treated (below $20 \mu \mathrm{m} / \mathrm{hr}$ ) or untreated controls (below 25 $\mu \mathrm{m} / \mathrm{hr}$ ).

These findings suggest that a significant proportion of growth cone collapse and avoidance responses and decrease in growth velocities is elicited by mammalian-like neurite growth inhibitors on Xenopus spinal cord oligodendrocytes.

\section{Myelin associated inhibitors can be detected in myelinated fiber tracts of Xenopus spinal cord but not in its optic nerve and tectum}

A method recently developed by Rubin et al. (1994) was applied using Mab IN-1 to visualize the distribution of mammalianlike neurite growth inhibitors in CNS myelin of Xenopus. To judge whether IN-1 immunoreactivity is, as in rats, localized on CNS myelin, myelinated tracts in the Xenopus nervous system were identified by antibodies against the myelin proteins PLP and MBP. Tadpoles and metamorphosing animals were included to determine the onset and extent of myelination and appearance of IN-1 staining during development.

Staining of transverse cryosections from adult Xenopus spinal 

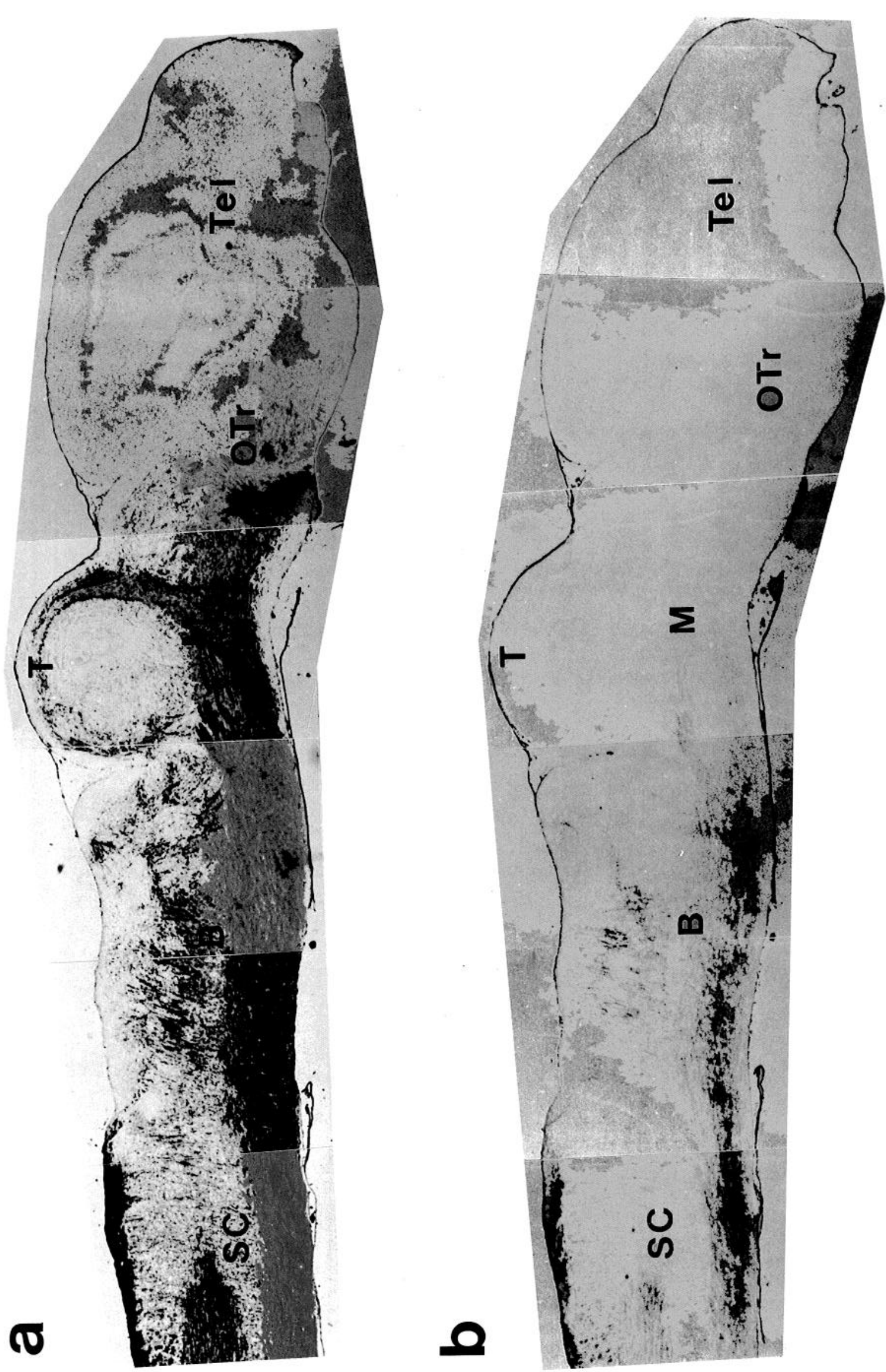

密

ธै

号瓷

余额

于

घี

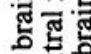

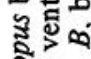

รัฐ

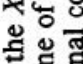

형응

흠ํํ

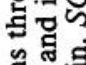

है 댕

石产

즘 징무

홍혀

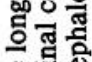

능

ํㅗㅇ

这

8 둥

5

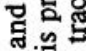

$\checkmark$ o

is

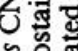

s. .

ํㅗㄹ

․ㅡㅁㅗ

密它害

ตำ

ช.

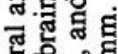

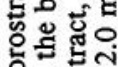

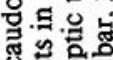

of

ปี ฮี

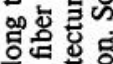

तु. 정

흥응

월

낭

号远

틀

7 娄

它氙嵒

응

\&율

额

골열

ท을 영

드.

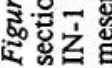



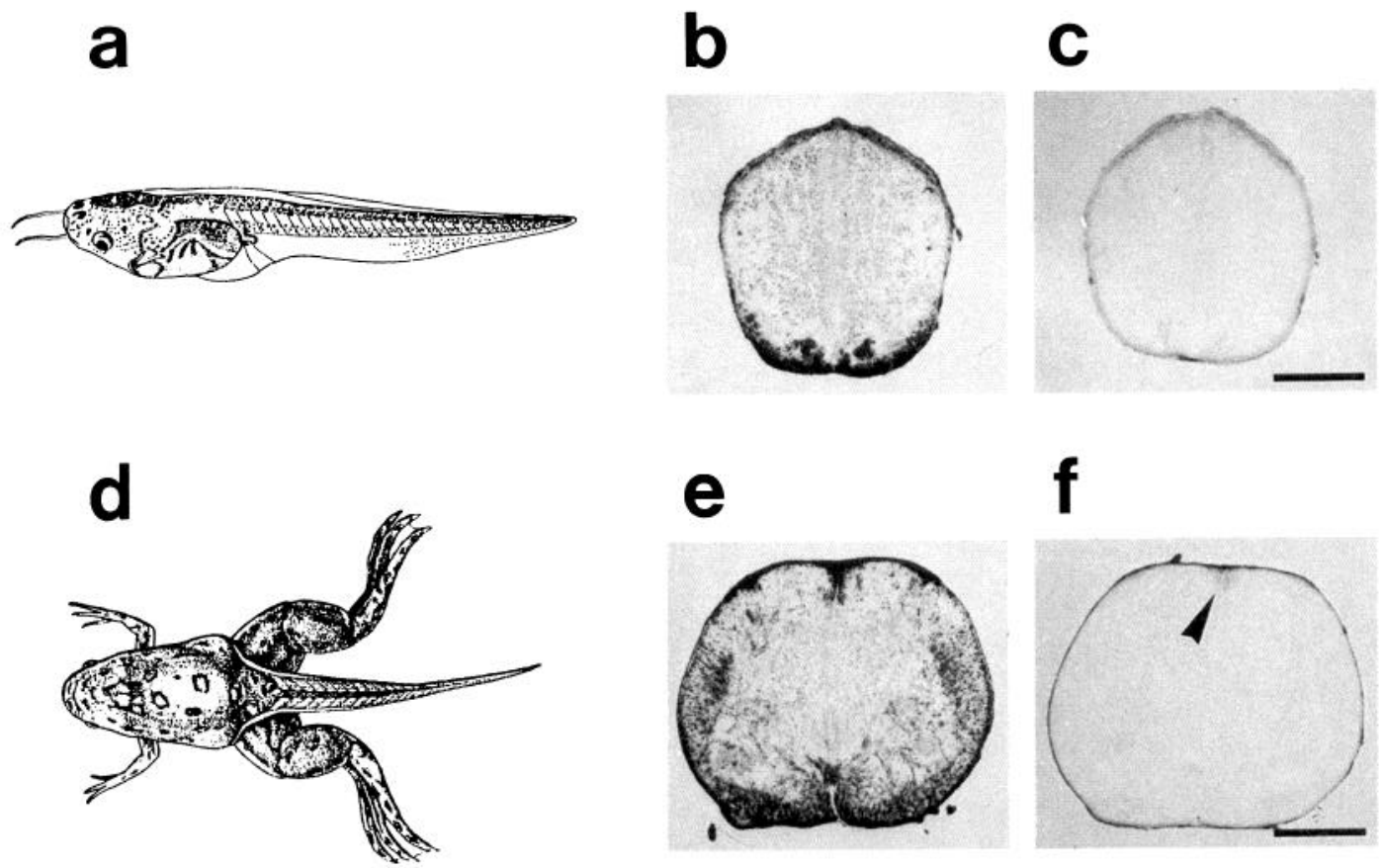

Figure 6. Appearance of $\mathrm{IN}-1$ immunoreactivity during development. $a$, Stage 51 Xenopus tadpole, from which sections in $b$ and $c$ were taken. $b$, Spinal cord section stained with anti-PLP. Myelinated fibers are solely detected at the ventral margin. $c$, A corresponding section treated with Mab IN-1 reveals no staining. $d$, Xenopus tadpole at metamorphic climax (stage 61), from which sections in $e$ and $f$ were taken. $e$, Spinal cord section stained with anti-PLP showing myelinated fibers in ventral, lateral and dorsal areas. $f$, A corresponding section treated with Mab IN-1 reveals no staining except for a small triangle in the dorsal funiculus (arrowhead). Drawings $a$ and $d$ were taken from Nieuwkoop and Faber (1957). Scale bars, $500 \mu \mathrm{m}$.

cord (Fig. 4a) with an antibody against MBP revealed dense staining of fiber tracts throughout the white matter, including the dorsal, the lateral and the ventral funiculus (Fig. $4 b$ ). The dorsal root entry zone adjacent to the dorsal funiculus also exhibited dense staining, whereas staining in the dorsal root next to the lateral funiculus was confined to isolated fiber tracts. Smaller fiber tracts that extended into the dorsal, lateral, ventrolateral, and ventromedial fields of the gray matter (Fig. $4 b$; nomenclature after Ebbeson and Northcutt, 1976) were also MBP positive. Anti-MBP also labeled the optic nerve, fiber tracts in the optic tectum and PNS nerves, such as the sciatic nerve (Fig. $4 d-i$ ). A nearly identical staining pattern was revealed with an antiserum against PLP (not shown). Thus, staining with antibodies against either of these myelin proteins is a valid marker for myelinated fiber tracts in the Xenopus nervous system.

Mab IN-1 labeling showed up exclusively in myelinated areas of the spinal cord (Fig. 4c), but it did not extend to smaller tracts crossing the gray matter. In control experiments, Mab IN-1 was omitted, but the remaining procedure identical, and no myelin associated staining was seen. Despite its intensive anti-MBP label, Xenopus sciatic nerve was not stained by IN-1 (Fig. 4h,i).

Unlike the spinal cord, neither optic nerve nor optic tectum stained with Mab IN-1 (Fig. 4e,g), although staining with antiPLP (Fig. $4 d, f$ ) and anti-MBP (not shown) both was of similar intensity as in spinal cord. Other mouse IgM class antibodies (anti-vimentin and Mab XC9D8 against an intermediate filament protein of Xenopus glial cells; Szaro and Gainer, 1988) produced their specific staining patterns that were different from that of Mab IN-1. This rules out nonspecific adsorption of IgM- class antibodies to Xenopus myelin. We also examined ultrathin sections of Xenopus optic nerve and spinal cord and found neither a striking difference in thickness of myelin around individual axons of spinal cord and optic nerve, nor a lower packing density of myelinated axons in the optic nerve that could account for the absence of IN-1 staining.

These findings indicate that myelin from adult Xenopus optic nerve and tectum has no detectable amount of mammalian-like myelin-associated inhibitors defined by Mab IN-1, whereas myelin from adult Xenopus spinal cord appears to possess them to a considerable degree.

In a first attempt to localize the border of expression of myelin-associated inhibitors in the CNS of adult Xenopus, IN-1 labeling in longitudinal cryosections of the brain and anterior portion of the spinal cord was compared with labeling by antiMBP and anti-PLP. Figure 5, $a$ and $b$, shows two adjacent sections, stained with anti-PLP and Mab IN-1, respectively. PLP immunostaining extends rostrally to the posterior and ventral portion of the telencephalon and includes the optic tract in the diencephalon and two distinct layers in the dorsal tectum and one in its ventral part. PLP staining was observed throughout the ventral and lateral brainstem and ventral funiculus of the spinal cord. Caudal to the obex, the dorsal root entry zone and the ventral, lateral, and dorsal funiculus were labeled. MBP immunostaining was identical to that of PLP (data not shown).

Mab IN-1 staining (Fig. $5 b$ ) in the spinal cord, brainstem, and ventral mesencephalon was parallel to that of anti-PLP and anti-MBP. No IN-1 staining was detected rostral to the mesencephalon, and optic tract and tectum were unlabeled. Because IN-1 staining decreases in intensity from brainstem toward rostral CNS, it is not possible to define a boundary. 
Myelin-associated inhibitors are not detectable in spinal cord of tadpoles prior to metamorphic climax

The degree of myelination in premetamorphic tadpoles was low, as judged by staining with antibodies against PLP (Fig. $6 b$ ) and MBP (not shown). In sections derived from the spinal cord of tadpoles (stage 51, Nieuwkoop and Faber, 1956; regions corresponding to those in adult frogs), MBP and PLP staining was restricted to a narrow zone in the ventral spinal cord corresponding to the positions of Mauthner axons (Fig. $6 c$ ). In the optic nerve and tectum, only a few myelinated fibers were detected (not shown). Labeling with Mab IN-1 was not observed in either of these structures.

Sections from tadpoles at the beginning of the metamorphic climax (Nieuwkoop and Fabcr stagc 61) cxhibited a far greater degree of myelination as judged by anti-PLP (Fig. $6 e$ ) and MBP staining (not shown), which was still below the level of the adult. Staining with Mab IN-1 became just detectable and was localized to a small triangle in the dorsal funiculus (Fig. 6f), but absent from the optic nerve, tectum or forebrain. Thus, IN-1 immunoreactivity in the spinal cord of metamorphosing tadpoles gradually follows myelination.

\section{Discussion}

The present experiments revealed a striking difference in substrate properties of CNS myelin and oligodendrocytes derived from Xenopus hindbrain/spinal cord or optic nerve/tectum. This difference correlates with the capacity of injured axons to regenerate in vivo in these tissues. Xenopus spinal cord myelin and oligodendrocytes possess nonpermissive substrate properties for growing axons in vitro, to which mammalian-like neurite growth inhibitors as defined by Mab IN-1 (Caroni and Schwab, 1988a,b) contribute to a considerable degree. In contrast oligodendrocytes and myelin derived from Xenopus optic nerve and tectum are growth-permissive substrates, and neurite growth inhibitors were not detectable. This difference in substrate properties and expression of neurite growth inhibitors correlates with the failure of axonal regeneration in the adult Xenopus spinal cord (Beattie et al., 1990) and the success of retinal axon regrowth in the optic nerve and tectum (Gaze, 1970). This correlation between in vitro and in vivo results extends to premetamorphic tadpoles where axonal regeneration, prior to the onset of myelination and the appearance of neurite growth inhibitors, proceeds successfully in both spinal cord (Beattie et al., 1990) and optic nerve (Gaze, 1970). Likewise, CNS myelin of the axolotl is a growth-permissive substrate in vitro. It does not exhibit neurite growth inhibitors, and axonal regeneration in vivo is successful (Gaze, 1970; Clarke et al., 1988).

The first indications of differences in substrate properties between optic nerve/tectum and hindbrain/spinal cord myelin of Xenopus were derived from the quantitative outgrowth assay. This assay has proven adequate for the evaluation of differential substrate properties of tectum-derived cell surface membranes of fish (Vielmetter and Stuermer, 1989) and for the comparison of substrate properties of CNS myelin of fish and rats (Bastmeyer et al., 1991). A critical evaluation of the assay was provided in these reports. Applied here for tests of amphibian CNS myelin, the outgrowth assays have shown that Xenopus optic nerve/ tectum myelin allows axon outgrowth to a similar extent as fish CNS myelin (Bastmeyer et al., 1991). Rat CNS myelin has proven to be a nonpermissive substrate for growth of axons of a variety of neuronal populations (Schwab and Caroni, 1988; Fawcett et al., 1990; Vanselow et al., 1990; Bandtlow et al., 1991; Moormann and Hume, 1993), including regenerating goldfish retinal axons (Bastmeyer et al., 1991), and this property is reflected in the present assay by poor outgrowth of axons from retinal explants. As compared to that of the rat, goldfish CNS myelin was described earlier as a permissive substrate (Carbonetto et al., 1987; Vanselow et al., 1990; Bastmeyer et al., 1991). This description is used here for Xenopus optic nerve/ tectum myelin and also applies to CNS myelin of the axolotl. Xenopus spinal cord myelin is, by comparison, a non-permissive substrate, in that outgrowth of axons was as poor as on rat CNS myelin (Bastmeyer et al., 1991).

The average of axon numbers reflects a clear difference of myclin substrate properties; however, this difference is in many instances larger. Roughly half of the explants show no or poor outgrowth, even on permissive myelin substrates, since they come to lie upside down on the substrate (see Materials and Methods). Since all explants are included in our counts, those with poor or no outgrowth lead to a reduction of the larger differences in number of axons on permissive versus nonpermissive myelin substrates.

Despite their permissive substrate properties, Xenopus optic nerve/tectum myelin, goldfish CNS myelin and myelin of the axolotl CNS do not represent particularly good substrates, since outgrowth of axons on either of these myelin fractions was far below that observed on laminin or cell surface membrane fractions largely free of myelin (Bastmeyer et al., 1991). Extrapolated to the situation in vivo, the present in vitro data may suggest that myelin and oligodendrocytes with permissive properties do not impair regrowth of injured axons. Additional growth supportive substrates may, however, be present in the tissues through which axons regenerate with vigor (Hopkins et al., 1985; Battisti et al., 1992; Strobel and Stuermer, 1994).

One reason for the nonpermissive substrate properties of Xenopus spinal cord-derived oligodendrocytes and myelin is, according to our present results, the presence of mammalian-like neurite growth inhibitors (Caroni and Schwab, 1988a,b). Evidence for the presence of mammalian-like growth inhibitors in Xenopus spinal cord oligodendrocytes and myelin was obtained from the observation of growth cone behavior in the presence and absence of the antibody IN-1 and through its immunocytochemistry. Unfortunately, cDNAs encoding the neurite growth inhibitors and probes for in situ hybridization are not yet available. Attempts to obtain appropriate immunoblots with $\mathrm{IN}-1$ failed, since this antibody bound unspecifically to numerous proteins of Xenopus myelin. Still, the finding that growth cones collapse and avoid spinal cord oligodendrocytes but cross them at significant higher frequencies and with an increase in velocity when IN-1 is present argues strongly for the existence of surface components, immunologically related to mammalian-like growth inhibitors in Xenopus spinal cord. On sections of the Xenopus CNS, Mab IN-1 recognizes a myelin-associated component, a result that closely resembles that obtained in the rat (Rubin et al., 1994). Furthermore, IN-1 immunoreactivity in Xenopus is, as in mammals, absent from the PNS (Rubin et al., 1994), and is seen only in those CNS areas whose myelin represents a nonpermissive substrate for axon growth. IN-1 immunoreactivity was undetectable in the axolotl spinal cord myelin (not shown), which in turn exhibited growth permissive substrate properties.

While IN-1 did improve the substrate properties of spinal 
cord oligodendrocytes, it had no such influence on their optic nerve/tectum-derived counterparts. IN-1 did not affect the proportion of axons that crossed (or avoided) optic nerve/tectum oligodendrocytes, nor did it improve the velocity of growth cone advancement along the surface of these cells. This, although both types oligodendrocytes closely resemble each other with respect to in vitro development, morphology and myelin marker-expression. Thus, evidence from different experiments converges and supports the view that IN-1 identifies mammalianlike neurite growth inhibitors in Xenopus that are present mainly in its spinal cord and hindbrain.

Mammalian oligodendrocytes elicit collapse of DRG growth cones quite efficiently even when only one or a few filopodia have contacted the cell (Bandtlow et al., 1990). In contrast to axons encountering mammalian oligodendrocytes goldfish and Xenopus retinal growth cones rarely collapsed upon contact with Xenopus spinal cord oligodendrocytes. Instead, they moved onto the membranous rims of the Xenopus oligodendrocytes and interacted with the cell before they retracted and collapsed, or grew around it. Several reasons may account for this less dramatic behavior. Xenopus spinal cord oligodendrocytes may have a lower concentration of collapse-inducing inhibitory activities, perhaps because they were induced to differentiate by forskolin, and may not yet have reached higher levels of inhibitor expression. All oligodendrocytes did express GalC and O1, but only $20 \%$ expressed the more advanced myelin markers MBP and PLP. While mammalian oligodendrocytes exhibit strong inhibitory activity concurrent with Ol (Caroni and Schwab, 1988 b), this may not be so in Xenopus. Another possibility is that the responsiveness of the retinal axons (goldfish and Xen$o p u s)$ to inhibitors on oligodendrocytes differs from that of axons tested in the other studies (Bandtlow et al., 1990; Kapfhammer et al., 1992). Roughly $60 \%$ of goldfish retinal growth cones did collapse upon contact with mammalian oligodendrocytes (Bastmeyer et al., 1991), but, as with Xenopus spinal cord oligodendrocytes, they first moved onto the membranous rims of the mammalian glia cells before responding with collapse. Furthermore, goldfish retinal axons often avoided the cells rather than collapsing (Bastmeyer et al., 1991). When exposed to rat CNS myelin instead of oligodendrocytes, goldfish growth cones were observed to grow onto the myelin particles. They exhibited ruffling of lamellipodia for hours but failed to advance (Bastmeyer et al., 1991). Thus, the degree of sensitivity of the axonswhether due to the density of presumed receptors, receptor conformation or links to second messenger pathways - may differ between neurons of various species and neuronal subtypes. This or the level of inhibitor expression could account for the rare collapse events. We shall be able to define the underlying mechanisms once the relevant molecules are better understood.

With respect to Xenopus oligodendrocyte development in vitro, our findings imply another interesting aspect. A large proportion of oligodendrocytes must be determined in premetamorphic Xenopus tadpoles to express neurite growth inhibitors at higher levels when from spinal cord and, conversely, at lower (at present undetectable levels) when from the optic nerve/tectum. This is because the oligodendrocytes were isolated from premetamorphic tadpoles or froglets, and elicited the described growth cone responses whether from the younger or older animal. We investigated whether thyroxin, which rises toward and promotes metamorphosis, would stimulate the one but not the other type, but found thyroxin receptors equally distributed in both (D. Lang, K. Damm, and C. Stuermer, unpublished results). It will be interesting to pursue which factors or conditions cause this diversity.

While neurite growth inhibitors are one reason for the nonpermissiveness of Xenopus oligodendrocytes they do not seem to be the only one, since oligodendrocytes from optic nerve/ tectum, which lack these inhibitors, also elicited avoidance responses in $40 \%$ of all growth cones. This degree of avoidance did not change in the presence of Mab IN-1. Moreover, growth cones reduced their growth velocity when crossing either type of oligodendrocyte, but continued their growth along immature oligodendrocytes without reduction in speed. Goldfish oligodendrocytes in vitro were found to even stimulate axonal regeneration along their surface and they express growth supportive molecules (Bastmeyer et al., 1993). This implies that all Xenopus oligodendrocytes, like differentiating oligodendrocytes of mammals, lose upon differentiation highly growth-supportive surface molecules and/or gain components that render the differentiated cell an unfavorable substrate for axon growth (Pesheva et al., 1989). Using the pertinent antibodies we investigated whether the cell surface molecule Janusin might be one of the presumed nonpermissive substrate molecules, but failed to find Janusin immunoreactivity on Xenopus oligodendrocytes (D. Lang, P. Pesheva, M. Schachner, and C. Stuermer, unpublished data). Whether Xenopus oligodendrocytes exhibit unfavorable substrate properties during retinal axonal regeneration in the Xenopus optic nerve or whether growth supportive molecules are upregulated and stimulate axonal regrowth remains to be seen.

There are other reasons besides oligodendrocyte/myelin inhibitors, for the failure of axonal regeneration, which are not addressed in the present study. Locally forming glial scars are considered important barriers for regenerating axons in mammals (Krueger et al., 1986), but such structures are crossed by retinal axons in the frog (Reier et al., 1983). On the other hand, tectal efferents in frogs fail to regenerate in tissues through which retinal axons pass readily (Lyon and Stelzner, 1987). Thus, neurons may differ in their capacity for axonal regeneration and response to the glia environment. Moreover, they differ in their dependence on neurotrophic factors (Korsching, 1993) that can influence survival, sprouting and elongation (Schnell et al., 1994) as well as cell body reactions (Thanos et al., 1989).

\section{References}

Bandtlow C, Zachleder T, Schwab ME (1990) Oligodendrocytes arrest neurite growth by contact inhibition. J Neurosci 10:3837-3848.

Bandtlow C, Schmidt MF, Hassinger TD, Schwab ME, Kater SB (1993) The role of intracellular calcium in NI-35-evoked collapse of neuronal growth cones. Science 259:80-83.

Bastmeyer M, Beckmann M, Schwab, ME, Stuermer CAO (1991) Growth of regenerating goldfish axons is inhibited by rat oligodendrocytes and CNS myelin but not by goldfish optic nerve/tract oligodendrocyte-like cells and fish CNS myelin. J Neurosci 11:626-640.

Bastmeyer M, Bähr M, Stuermer CAO (1993) Fish optic nerve oligodendrocytes support axonal regeneration of fish and mammalian retinal ganglion cells. Glia 8:1-11.

Battisti WP, Shinar Y, Schwartz M, Levitt P, Murray Mm (1992) Temporal and spatial patterns of expression of laminin, chondroitin sulphate proteoglycan and HNK-1 immunoreactivity during regeneration in the goldfish optic nerve. J Neurocytol 21:557-573.

Beattie MS, Bresnahan JC, Lopate G (1990) Metamorphosis alters the response to spinal cord transection in Xenopus laevis frogs. J Neurobiol 21:1108-1122.

Carbonetto S, Evans D, Cochard P (1987) Nerve fiber growth in culture on tissue substrates from central and peripheral nervous systems. J Neurosci 7:610-620.

Caroni P, Schwab ME (1988a) Two membrane fractions from rat 
central myelin with inhibitory properties of neurite growth and fibroblast spreading. J Cell Biol 106:1281-1288.

Caroni P, Schwab ME (1988b) Antibody against myelin-associated inhibitor of neurite growth neutralizes nonpermissive substrate properties of CNS white matter. Neuron 1:85-96.

Clarke JDW, Alexander R, Holder N (1988) Regeneration of descending axons in the spinal cord of the axolotl. Neurosci Lett 89:1-6.

Colman DR, Kreibich G, Frey AB, Sabatini DD (1982) Synthesis and incorporation of myelin polypeptides into CNS myelin. J Cell Biol 95:598-608.

Ebbeson SOE, Northcutt RG (1976) Morphology of the spinal cord. In: Neurobiology of the frog (Llinas R, Precht W, eds). Berlin: Springer.

Fawcett JW, Rokos J, Bakst I (1989) Oligodendrocytes repel axons and cause growth cone collapse. J Cell Sci 92:93-100.

Forehand CJ, Farel PB (1982) Anatomical and behavioral recovery from the effects of spinal cord transection: dependence on metamorphosis in anuran larvae. J Neurosci 2:654-662.

Gaze RM (1970) The formation of nerve connections. London: Academic.

Hopkins JM, Ford-Holevinski TS, McCoy JP, Agranoff BW (1985) Laminin and optic nerve regeneration in the goldfish. $J$ Neurosci 5:3030-3038.

Kapfhammer J, Schwab ME, Schneider GE (1992) Antibody neutralization of neurite growth inhibitors from oligodendrocytes results in expanded pattern of postnatally sprouting retinocollicular axons. J Neurosci 12:2112-2119.

Keirstad HS, Hasan SJ, Meir GD, Steeves JD (1992) Suppression of the onset of myelination extends the permissive period for the functional repair of embryonic spinal cord. Proc Natl Acad Sci USA 89: 11664-11668.

Korsching S (1993) The neurotrophic factor concept: a re-examination. J Neurosci 13:2739-2748.

Krueger S, Sievers J, Hansen C, Sadler M, Berry M (1986) Three morphologically distinct types of interface develop between adult host and fetal brain transplants: implications for scar formation in the adult central nervous system. J Comp Neurol 249:103-116.

Landreth GE, Agranoff BW (1976) Explant culture of adult goldfish retina: effect of prior optic nerve crush. Brain Res 118:299-303.

Lang D, Rubin B, Schwab ME, Stuermer CAO (1993) Neurite growth inhibitors (NI) of mammalian CNS myelin are present in Xenopus spinal cord but not in the optic nerve. Soc Neurosci Abstr 19:1738.

Lyon MJ, Stelzner DJ (1987) Tests of the regenerative capacity of tectal efferent axons in the frog, Rana pipiens. J Comp Neurol 255: $511-525$.

Moorman SJ, Hume RI (1993) $\Omega$-conotoxin prevents myelin-evoked growth cone collapse in neonatal rat locus coeruleus neurons in vitro. J Neurosci 13:4727-4736.

Nieuwkoop PD, Faber J (1956) Normal table of Xenopus laevis (Daudin). Amsterdam: North Holland.
Pesheva P, Spiess E, Schachner M (1989) J1-160 and J1-180 are oligodendrocyte-secreted non-permissive substrates for cell adhesion. J Cell Biol 109:1765-1778.

Piatt J (1955) Regeneration of the spinal cord in the salamander. J Exp Zool 129:177-207.

Reier PJ, Stensaas LJ, Guth L (1983) The astrocytic scar as an impediment to regeneration in the central nervous system. In: Spinal cord reconstruction (Kao CC, Bunge RP, Reier PJ, eds), pp 163-193. New York: Raven.

Rubin B, Dusart J, Schwab ME (1994) A monoclonal antibody (IN1) which neutralizes growth inhibitory proteins in the rat central nervous system recognizes antigens localized in CNS myelin. $\mathbf{J}$ Neurocytol, in press.

Schnell L, Schneider R, Kolbeck R, Barde YA, Schwab ME (1994) Neurotrophin-3 enhances sprouting of corticospinal tract during development and after adult spinal cord lesion. Nature 367:170-173.

Schwab ME, Caroni P (1988) Oligodendrocytes and CNS myelin are non-permissive substrates for neurite growth and fibroblast spreading in vitro. J Neurosci 8:2381-2393.

Schwab ME, Kapfhammer J, Bandtlow CE (1993) Inhibitors of neurite growth. Annu Rev Neurosci 16:565-595.

Sharma SC, Jadhao AG, Prasada Rao PD (1993) Regeneration of supraspinal projection neurons in the adult goldfish. Brain Res 620 : 221-228.

Sommer J, Schchner M (1981) Monoclonal antibodies (O1 to O4) to oligodendrocyte cell surfaces: an immunocytological study in the central nervous system. Dev Biol 83:311-327

Stensaas LJ, Feringa ER (1977) Axon regeneration across the site of injury in the optic nerve of the newt Triturus pyrrhogaster. Cell Tissue Res 179:501-516.

Strobel G, Stuermer CAO (1994) Growth cones of regenerating retinal axons contact a variety of cellular profiles in the transected goldfish optic nerve. J Comp Neurol, in press.

Stuermer CAO, Lang D (1993) Xenopus spinal cord-but not optic nerve-derived oligodendrocytes inhibit growth cone elongation. Soc Neurosci Abstr 19:422.

Szaro BG, Gainer H (1988) Immunocytochemical identification of non-neural intermediate filament proteins in the developing Xenopus laevis nervous system. Dev Brain Res 43:207-224.

Thanos S, Bähr M, Barde YA, Vanselow J (1989) Survival and axonal elongation of adult rat retinal ganglion cells. Eur J Neurosci 1:19-26.

Turner JE, Singer $M$ (1974) The ultrastructure of regeneration in the severed newt optic nerve. J Exp Zool 190:249-268.

Vanselow J, Schwab ME, Thanos S (1990) Responses of regenerating rat retinal ganglion cell axons to contacts with central nervous myelin in vitro. Eur J Neurosci 2:121-125.

Vielmetter J, Stuermer CAO (1989) Goldfish retinal axons respond to position-specific properties of tectal cell membranes in vitro. Neuron 2:1331-1339. 